\title{
Different Incidence of Endocrine Disrupting Activity in Female Pigs Kept at High and Low Stocking Densities
}

\section{László Makay*}

Department of Veterinary Medicine, Veterinary Medical Station of Békéscsaba, 2000 Szentendre, Sztaravodai u. 42, Hungary

*Corresponding author: László Makay, Department of Veterinary Medicine, Veterinary Medical Station of Békéscsaba, 2000 Szentendre, Sztaravodai u. 42, 2000 Szentendre, Sztaravodai u. 42, Hungary

Received: January 16, 2017; Accepted: February 27, 2017; Published: March 01, 2017

\begin{abstract}
Background: The objective of this field study was to attempt to clarify why different kinds of feedback reactions can occur in response to the administration of the same large-dose oestrogen hormone to pigs. These trials were conducted at a time when the hormonal castration of female pigs with a large dose of oestrogen was still officially licensed.
\end{abstract}

The solution of this puzzle became possible after it had come to light that the medicament diethylstilboestrol (DES) used for hormonal castration of female pigs was an endocrine disruptor too. Besides, it had in the meantime been discovered that normally the hypothalamic-pituitary-gonadal axis of a healthy pig is able to overcome this disrupting effect by a positive feedback reaction when the progesterone produced suppresses the cyclic ovarian function.

Results: Whenever some additional stressor burdens simultaneously the reproductive endocrine system, it may become unable to get the upper hand over the disrupting effect and the negative feedback is bound to happen. Thus the reproductive endocrine system, without the protective effect of progesterone, makes way for the endocrine disruption. This is indicated by the serious follicular depression.

Conclusions: As a result of the examinations it can be concluded that some stressors of environmental or social origin may increase the predisposition to endocrine disruption. This incidence of elevated endocrine disrupting activity seems to be in direct proportion to the high stocking density the animals are exposed to.

Keywords: Ovary; Corpora lutea; Progesterone; Gonadotrophin; Pig

\section{Abbreviations}

DES: Diethylstilbestrol (Synthetic Nonsteroid Estrogen); Gnrh: Gonadtropin Releasing Hormone; HCG: Human Chorionic Gonadotropin Hormone; IU: International Unit

\section{Background}

This paper gives account of an endocrinological field research that demonstrates some specific versions of the positive (self-protecting) and negative reproductive endocrine feedback reactions. As outlined in a previous paper [1], the female pig's reproductive endocrine system responds to the parenteral administration of a large dose of oestrogen such as diethylstilboestrol (DES), with a positive feedback reaction whenever it is able to produce it, and not by a negative one as believed previously $[2,3]$. In the absence of such an ability, the temporary reactivity of the hypothalamic-pituitary-gonadal axis is inadequate and a negative feedback reaction develops.

During the time of these field trials between 1962 and 1974, it was generally believed that the most evident endocrine response to an increased hormone level is a simple negative feedback reaction. This seemed obvious as it tended to decrease the elevated hormone level back down to a normal level. A widely known example of this is the decrease in corticosteroid production by the adrenal cortex due to the effect of exogenous corticosteroid hormone administration.
However, it was later proposed that the reproductive endocrine system has a particular ability for an immediate active response in the form of a self-protecting positive feedback reaction [1]. This came about as a result of the observation that the positive and negative feedback reactions can be differentiated by inspection of the ovarian structures. The ovarian signs of the two different feedback reactions are spectacular and demonstrative. The ovaries of pigs with a positive feedback reaction were large $(30-45 \mathrm{~mm}$ in diameter) with 5-14 corpora lutea. In contrast, the ovaries of pigs with a negative feedback reaction were small (10-15 $\mathrm{mm}$ in diameter), they did not contain any follicle or corpus luteum, and their smooth surface showed signs of strong follicular depression (Figure 1). It was reported that the percentage of positive feedback cases in herds with less than 8-10 pigs kept together in one pen was $75.2 \%$ in gilts (Table 1) [1] and $88.1 \%$ in adult sows [4]. However, by 1962 it had been shown that in herds comprising 20-35 pigs per pen, the outcome of hormonal castration was quite different. The results were unpredictable and unreliable. It was thought that when the number of animals kept together (pen density) is increased this could cause a level of discomfort among the pigs that would be able to influence vital behaviours (appetite, ability to rest, etc.). The cause of this was never clarified satisfactorily, only assumptions were available. The most widely held theory was that in larger groups it was impossible to select the optimum time of treatment among randomly cycling animals. However, this was not 
Table 1: Results of the number and proportion of the animals' responses to parenteral DES administration in this study and in a previous study [13]

\section{Pen density:}

8 to 10 pigs per pen [13] 20 to 35 pigs per pen N\%

$\mathrm{N} \%$

Positive feedback cases$$
206
$$

$75.2 \%$

3

$3.5 \%$

Negative feedback cases

68

$24.8 \%$

83

$96.5 \%$

Total number of pigs

274

$100 \%$

86

$100 \%$

Fisher's exact $P<0.0001$

possible in smaller groups either.

The objective of the experiments presented here was to attempt to clarify this issue in a period of time when the use of large dose oestrogen such as DES in pigs was still officially licensed and gonadotropin releasing hormone $(\mathrm{GnRH})$ was not available yet. The solution of this puzzle became possible after it had come to light that the medicament diethylstilboestrol (DES) used for hormonal castration of female pigs itself was an endocrine disruptor too.

It had also been discovered that normally the hypothalamicpituitary-gonadal axis of a healthy pig is able to overcome this disrupting effect by a positive (successful) feedback reaction when the progesterone produced by the corpora lutea suppresses the cyclic ovarian function [1]. Nevertheless whenever some additional factor (stressor) burdens simultaneously the reproductive endocrine system, it may become unable to get the upper hand over this disrupting effect and the negative (unsuccessful) feedback is bound to happen. Thus the reproductive endocrine system, without the protective effect of progesterone, makes way for the endocrine disruption. This is indicated by the serious follicular depression (Figure 1).

The incidence of elevated endocrine disrupting activity seems to be in direct proportion to the high stocking density the animals are exposed to. The aim of the hormonal casatration or hormonal sterilization used to be the elimination of the perturbing effect of the cyclic repetition of oestrus $[5,6]$.

\section{Materials and Methods}

The experiments were conducted from 1962 to 1974 and had been approved by the director of the Veterinary Medical Station of B k scsaba, Hungary [7]. The examinations took place in pig herds consisting of multiple units where 20-35 pigs were kept in one pen. The experiments involved a total of 86 gilts from 2 pig herds in county B k s, Hungary. After this period of practical examinations the working up of the theme followed, up to 2014.

Hungarian White meat-type or crossbred, 6 to 9 months old gilts were used in the experiments. Approximately half of the animals were gilts and the rest were castrated hogs in the same pig herd. The medicines were Syntestrin forte injection ad usum veterinarium that contained $10 \mathrm{mg}$ DES per $\mathrm{ml}$, and Choriogonin injection containing 1500 or 3000 international units (IU) human chorionic gonadotrophin (hCG) hormone in ampoule. Both products were manufactured by Gedeon Richter Chemical Works Co. Ltd. Budapest, Hungary. Each pig received $0.5 \mathrm{mg} / \mathrm{kg}$ DES parenterally. The type of the feedback reaction elicited was determined based on the clinical signs shown by the pigs and by examination of the external and internal genital organs. The uteri and ovaries were inspected at the time of slaughter.

The results of these experiments were compared to those found in previous experiments [1] using cross-tabulation and Fishers exact test.

\section{Results}

Over a period of 10 to 30 (or even more) days after injection the gilts showed signs of restlessness as a result of the prolonged oestrus (nymphomania). Only 3 gilts (3.5\%) calmed down a few days after the injection exhibiting signs of the positive feedback reaction (tranquillity, good appetite, inclination to rest). The remaining 83 gilts (96.5\%) exhibited signs of a negative feedback reaction (restlessness, reduced appetite, bothering of the other animals). Three days after the first treatment, 79 out of these 83 gilts were each administered 3000 IU of hCG inj. The remaining 4 gilts were used as controls and left untreated. The signs of nymphomania in the 79 injected gilts decreased and then ceased within a few days, indicating the transformation of the negative feedback reaction into a positive one. Meanwhile, the four control gilts continuously showed pronounced signs of nymphomania. To avoid further economic loss to the farm, on the $9^{\text {th }}$ day these four control gilts each also were administered an injection containing $3000 \mathrm{IU}$ of hCG. Within a few more days' time, these four animals also calmed down, showing signs of a positive feedback reaction.

The current results show that a significantly lower proportion of gilts (3/86 or $3.5 \%)$ experienced positive feedback reactions in herds with pig densities of 20-35 compared with the results obtained in prior experiments with less than 8-10 pigs per pen where 75.2\% (206/274) gilts experienced positive feedback reactions $(\mathrm{P}<0.0001$, Table 1$)$.

\section{Discussion}

The results demonstrate that in pig herds with higher stocking densities of 20-35 pigs per pen, positive feedback reactions occurred very rarely (3.5\%), while the rate of negative feedback reactions was much larger at $96.5 \%$ compared to $24.8 \%$ in pig herds with lower stocking densities of less than 8-10 pigs per pen [1]. These results demonstrate that in response to the administration of the same hormone to pigs, sometimes different feedback reactions develop. This may be the manifestation of some endocrine disrupting effect, suggesting that the function of the hypothalamic pituitary gonadal axis may be affected differently with different stocking densities.

Making an attempt to determine the cause of this phenomenon, one has to consider the possibility that in higher density pens the endocrine system loses the ability to respond to a large dose of exogenous oestrogen (DES) with the proper positive feedback reaction, perhaps as a result of some sort of social or environmental 


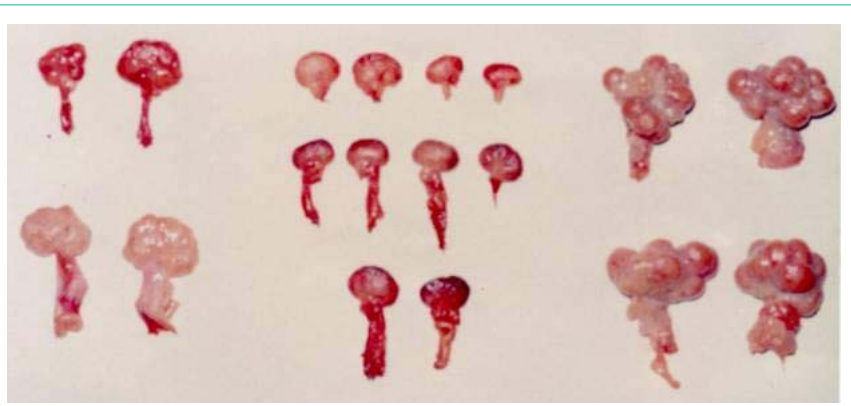

Figure 1: The signs of the negative and positive feedback reactions are spectacular and demonstrative.

This is shown in these images of ovaries from untreated gilts (left), follicular depression (negative feedback reaction) evoked by DES treatment and the elevated endocrine-disrupting activity (middle) and luteal phase (positive feedback reaction) brought about by the treatment (right).

stress. Recent publications [8,9] suggest that some chemicals, at certain doses, may act as endocrine disruptors. These can interfere with certain endocrine functions. It appears possible that in the development of endocrine disrupting activity certain stressors of environmental (social) origin may play an important part.

Now it is generally known that DES is the most potent endocrine disruptor identified to date [9]. Nevertheless the results of a previous study show that the endocrine system of the majority of pigs housed in smaller groups is able to prevent the disrupting effect of DES by a positive feedback response (self-protecting adaptation reaction) [1]. However, when another stressor such as higher stocking density simultaneously burdens the reproductive endocrine system, a positive feedback reaction cannot develop and, without this self-protecting effect, the disruption is bound to happen. This seems to indicate that in addition to chemicals also other factors, e.g. environmental or social stressors may play important part in the development of disrupting activity. However, if we stimulate the function of the reproductive endocrine system by the administration of hCG, the negative feedback reaction can be changed to a positive one. It has been shown that increasing population density can intensify the stress effect exerted on the animals [10]. As a result, the birth rate can decrease, which might even lead to population collapse [10]. Another important finding [2] is that the increased production of stress hormones represses the secretion of gonadotrophic hormones. Both of these findings are indicative of a relationship between stress and the biology of reproduction [11-13]. All these observations call attention to the fact that high population density in pig production should be regarded as a critical factor and should be taken into consideration when trying to maximize reproductive success $[14,15]$.

The results of this study show that keeping pigs in densely packed pens may adversely affect the function of the hypothalamic-pituitarygonadal axis $[16,17]$. The evidence suggests that this axis loses the ability to respond with a positive feedback reaction and this is likely to be due to the manifestation of an endocrine disrupting activity. However, if the activity of the reproductive endocrine system is supported by the administration of hCG hormone, the negative feedback reaction can be transformed into a positive one. Further studies are required to investigate the findings and assumptions presented in this manuscript. If the present findings could be corroborated, then it could even be established that the decrease found in the number of positive feedback reactions and the increase seen in the rate of negative feedback responses can be regarded as indicators of the extent of stress and similarly that of the elevated endocrine disrupting activity present in large pig farms [18-20].

\section{Conclusions}

As a result of the examinations it can be concluded that some stressors of environmental or social origin may increase the predisposition to endocrine disruption [21]. Accordingly, keeping pigs in densely populated pens may adversely affect the function of the hypothalamic-pituitary-gonadal axis. If this axis loses the ability to respond with a positive feedback reaction, it may give way to the manifestation of the endocrine disrupting activity. The incidence of elevated endocrine disrupting activity seems to be in direct proportion to the high stocking density the animals are exposed to.

\section{Acknowledgement}

The author would like to express his special thanks to Professor Dr. S ndor Gy rgy Fekete, DVM, DSc, Budapest, Hungary, Professor Dr. P ter Laczay DVM, DSc, Budapest, Hungary and late Professor Dr. Gyula Huszenicza DVM, DSc, Budapest, Hungary for their helpful advices.

Statement on ethics approval and consent the examinations with animals (pigs) were approved by the director of the Veterinary Medical Station of B k scsaba, Hungary. Humans were not involved, so it is not applicable.

\section{References}

1. Makay L. Solution of an old endocrinological puzzle. The rise and fall of an endocrinological doctrine. Hungarian Veterinary Journal (Magyar llatorvosok Lapja). Budapest. 2012; 134: 663-668.

2. Tangl H. A vitaminok, hormonok s antibiotikumok szerepe az llatteny szt sben (The Role of Vitamins, Hormones and Antibiotics in Animal Breeding). Akad miai Kiad, Budapest, 1959: 320.

3. Torday F. and Dratsay Gy. H z sert sek kezel se t szohormonnal (Treatment of fattening pigs with estrogen). Magyar llatorvosok Lapja. 1954; 9: 280-283.

4. Rako A, Sokola D, Bacic V, and Findrik M. Hormonal suppression of oestrus for fattening sows. Schweizer Archiv f r Tierheilkunde. 1952; 94: 658-670.

5. Bajez E. Mast- und Sterilizations versuche bei Schweinen mit hohen Dosen strogener Wirkstoffe. Wiener Tier rztliche Monatsschrift. 1954; 41: 226-228.

6. Corrias A. Suppression of oestrus in pigs by means of synthetic oestrogens. Progresso de la veterinaria, Torino. 1952; 7: 757-776.

7. Cunningham JG. Textbook of Veterinary Physiology. Third edition Philadelphia. 2002; 331.

8. Anderson AM, et al. Special issue on the impact of endocrine disruptors on reproductive health. Reproduction. $7^{\text {th }}$ Copenhagen Workshop on Endocrine Disruptors. 2013.

9. Khetan, Sushil K. Endocrine disruptors in the environment. J Wiley and Sons, Inc. New Jersey. 2014

10. Hall ET. The Hidden Dimension. Anchor Books Edition. A Division of Random House, Inc., New York. 1990.

11. Hunter RHF. Physiology and Technology of Reproduction in Female Domestic Animals. Academic Press Inc. London. 1980: 365-366.

12. Johnson MH and Everitt BJ. Essential Reproduction. Blackwell, Malden, MA, USA. 2007; pp: 108-109 and 113.

13. Kassotis CD, Tillit DE, et al. Estrogen and androgen Receptor Activities of 
Hydraulic Fracturing Chemicals and Surface and Ground Water in a DrillingDense Region. Endocrinology. 2014; 155: 897-907.

14. Kment A and Halama A. Ergebnisse der hormonalen Kastration weiblicher Schweine mit Stilb strolpr paraten. Wiener Tier rztliche Monatsschrift. 1952 39: 523-525.

15. McDonald's Veterinary Endocrinology and Reproduction (edited by M. H Pineda). lowa State University. Iowa State Press. Fifth edition. 2003.

16. Miller LA, Johns BE, Elias DJ, Crane KA. Efficacy of immunocontraceptive vaccines. Vaccine. 1997; 15, 1858-1862.
17. Ptaszynska M. Compendium of Animal Reproduction. Intervet International bv, Boxmeer. The Netherlands. 2009: 117-120.

18. Selye H. The Stress of Life. New York: McGraw-Hill Companies. Inc. 1975

19. Tangl H. A k rnyezet szerepe (The Role of the Environment). Akad miai Kiad. Budapest, 1965.

20. The Merck Veterinary Manual, $9^{\text {th }}$ edition. Merck and Co. Inc., USA. 2005.

21. Torday F. Adatok az th napos kor koc k nemi ciklus ra (Data on the sexual cycle of 5 months old gilts). Magyar llatorvosok Lapja. 1975; 12: 848.
Austin J Vet Sci \& Anim Husb - Volume 4 Issue 1 - 2017

ISSN: 2472-3371 | www.austinpublishing group.com

Makay. (C) All rights are reserved
Citation: Makay L. Different Incidence of Endocrine Disrupting Activity in Female Pigs Kept at High and Low Stocking Densities. Austin J Vet Sci \& Anim Husb. 2017; 4(1): 1029. 